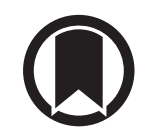

CrossMark

\title{
No impact of passive smoke on the somatic profile of lung cancers in never-smokers
}

\author{
Sébastien Couraud, Didier Debieuvre, Lionel Moreau, Patrick Dumont, \\ Jacques Margery, Elisabeth Quoix, Bernard Duvert, Laurent Cellerin, \\ Nathalie Baize, Bruno Taviot, Marie Coudurier, Jacques Cadranel, \\ Pascale Missy, Franck Morin, Jean-François Mornex, Gérard Zalcman and \\ Pierre-Jean Souquet on behalf of the BioCAST/IFCT-1002 study investigators
}

Affiliation: For a list of the authors' affiliations see the Acknowledgements section.

Correspondence: Sébastien Couraud, Hospices Civils de Lyon, CH Lyon Sud, Service de Pneumologie, 165 chemin du Grand Revoyet, F-69495 Pierre Bénite Cedex, France. E-mail: sebastien.couraudachu-lyon.fr

ABSTRACT EGFR and HER2 mutations and $A L K$ rearrangement are known to be related to lung cancer in never-smokers, while KRAS, BRAF and PIK3CA mutations are typically observed among smokers. There is still debate surrounding whether never-smokers exposed to passive smoke exhibit a "smoker-like" somatic profile compared with unexposed never-smokers.

Passive smoke exposure was assessed in the French BioCAST/IFCT-1002 never-smoker lung cancer cohort and routine molecular profiles analyses were compiled.

Of the 384 patients recruited into BioCAST, 319 were tested for at least one biomarker and provided data relating to passive smoking. Overall, 219 (66\%) reported having been exposed to passive smoking. No significant difference was observed between mutation frequency and passive smoke exposure (EGFR mutation: $46 \%$ in never exposed versus $41 \%$ in ever exposed; KRAS: $7 \%$ versus $7 \%$; ALK: $13 \%$ versus $11 \%$; HER2: $4 \%$ versus 5\%; BRAF: $6 \%$ versus $5 \%$; PIK3CA: $4 \%$ versus $2 \%$ ). We observed a nonsignificant trend for a negative association between EGFR mutation and cumulative duration of passive smoke exposure. No association was found for other biomarkers.

There is no clear association between passive smoke exposure and somatic profile in lifelong, never-smoker lung cancer.

@ERSpublications

Never-smokers with lung cancer exposed to passive smoke do not have a smoker-like somatic mutation profile http://ow.ly/Eheoi

For editorial comments see Eur Respir J 2015; 45: 1214-1217 [DOI: 10.1183/09031936.00046915]

This article has supplementary material available from erj.ersjournals.com

Received: May 272014 | Accepted after revision: Nov 102014 | First published online: March 052015

Clinical trial: This study is registered at www.clinicaltrials.gov with identifier number NCT01465854.

Support statement: The BioCAST/IFCT-1002 study was funded by research grants from AstraZeneca, Boehringer-Ingelheim, Lilly, Pfizer, Pierre-Fabre and Roche. Funding for this article has been deposited with FundRef. Those awarding funding had no role in the design, analysis or interpretation of the results, and the authors thus worked independently.

Conflict of interest: Disclosures can be found alongside the online version of this article at erj.ersjournals.com

Copyright CERS 2015 


\section{Introduction}

Approximately one-third of adults and $40 \%$ of children are exposed to second-hand smoke worldwide, which accounts for $1 \%$ of all-cause mortality [1]. This exposure is estimated to cause $>21000$ lung cancer-related deaths annually. Passive smoking is a well-known risk factor for lung cancer in never-smokers (LCINS) [2]. Lifelong never-smokers living with a smoker have an estimated 26\% increased risk of lung cancer (95\% CI 7-47\%), with both a dose-response and dose-duration relationship [3]. Similar results have been found for exposure in the workplace and during childhood $[4,5]$. In a recent French study, we reported that $66 \%$ of LCINSs had been exposed to passive smoke, especially women and those exposed in domestic settings $[6,7]$.

The somatic mutation pattern in non-small cell lung cancers (NSCLCs) can vary widely according to smoking status. Never-smokers are known to carry a higher frequency of EGFR (epidermal growth factor receptor) and HER2 (human epidermal growth factor receptor 2)/ERBB2 (v-Erb-b2 avian erythroblastic leukaemia viral oncogene homologue 2) mutations, and $A L K$ (anaplastic lymphoma kinase) rearrangement. In contrast, KRAS (Kirsten rat sarcoma viral oncogene homologue), BRAF (v-Raf murine sarcoma viral oncogene homologue B) [2, 8-12] and PIK3CA (phosphatidylinositol-3-kinase, catalytic subunit $\alpha$ ) [8] mutations are thought to be linked to active smoking.

We thus hypothesised that the profile of somatic mutation in patients who were never-smokers and exposed to passive smoking could represent a "smoker-like" pattern, potentially differing from the profile of never-smokers who had never been exposed to passive smoking. Controversial results have been reported regarding an EGFR mutation profile of never-smokers exposed to passive smoking that proved similar to those observed in smokers [13-16]. It was our belief that in never-smokers, somatic alterations (KRAS, BRAF and PIK3CA) were more frequent, while EGFR, HER2/ERBB2 and ALK alterations were not.

Here, we report the profile of the principal somatic alterations (EGFR and KRAS mutations, and ALK alteration) in a never-smoker BioCAST study, involving a large cohort of French LCINS [17], according to their exposure to passive smoking, as well as for the profile of low-frequency mutations (HER2/ERBB2, $B R A F$ and PIK3CA). Our study applied a multivariate approach and, overall, we found no significant difference.

\section{Method}

Population

For this study, we used data from the nationwide BioCAST/IFCT-1002 cohort of LCINS in France. The study design has been reported elsewhere [18] and our principal results appear in this issue of the European Respiratory Journal [7]. Briefly, BioCAST is a prospective, multicentre, observational study designed to describe the clinical, pathological and molecular epidemiology of LCINS in a French population. This study enrolled consecutive, newly diagnosed NSCLC patients who professed themselves to be never-smokers (smoked $<100$ cigarettes in their lifetime). Patients were surveyed using a standardised questionnaire during a pre-planned phone interview with a member of the study team. This 17-page questionnaire requested information on demographics, occupational exposure [19], exposure to domestic pollution, and personal and familial medical history, as well as some lifestyle, hormonal and reproductive factors (women only). Additional medical data were collected directly from participating physicians.

The study was conducted in 75 centres throughout metropolitan France, from November 1, 2011, to January 31, 2013, and sponsored by the French Intergroup for Thoracic Oncology (IFCT). The IFCT research staff was in charge of administrative management and quality assurance in compliance with international research standards.

The Sud-Est IV (Lyon, France) ethics committee approved the study protocol on September 13, 2011. The Advisory Committee on Information Processing for Health Research (CCTIRS) authorised the use of a computerised database on September 8, 2011, and the National Commission for Data Protection (CNIL) was consulted on September 23, 2011, in accordance with French law. The BioCAST study was registered on the US National Institutes of Health website, at www.clinicaltrials.gov, under the identifier NCT01465854.

Within the BioCAST dataset used for the study, we determined patients who were self-declared as having ever been exposed to passive smoking, and had at least one biomarker test available for EGFR, HER2, KRAS, BRAF, PIK3CA and ALK.

\section{Passive smoking exposure}

Passive smoking exposure was self-declared by patients and reported on the standardised questionnaire. Exposure to passive smoke in a domestic setting was defined as "living in the same house as at least one 
smoker for at least 1 year". Passive smoking exposure at the workplace was defined as "working with at least one smoker in the same closed room for at least 1 year". For this category, we retained only those who declared having worked with at least one smoker for the entire day, excluding exposure during breaks only or part-time days. Overall exposure was defined as a patient who reported being "ever exposed" to passive smoking either in a domestic setting or the workplace, or both. We also asked if patients had been exposed in a domestic setting before the age of 18 years old, usually considered as childhood age, or not.

For each patient declared as ever exposed, we additionally asked for the number of index smokers and the number of years of exposure to each index smoker. We then proceeded to calculate two additional variables for each domestic and workplace exposure: 1) the cumulative duration of exposure (CDE), computed as the sum of years exposed to passive smoking from each identified index-smoker; and 2) passive smoker-years (PSYs), computed as number of index smokers multiplied by the number of years of exposure to each index smoker. The corresponding variables for overall exposure to passive-smoke were obtained from a sum of the values calculated in a domestic setting and in the workplace.

\section{Tumour somatic mutation analysis}

The French National Cancer Institute (INCa) launched a network of 28 molecular genetics platforms, which provide routine cancer molecular testing for all patients [20]. Despite the variability of sample processing and analysis techniques in the corresponding laboratories, previous studies have reported the high quality of these analyses in thoracic oncology [21]. Each participating BioCAST physician was asked to systematically order tests for somatic mutations in EGFR and KRAS, as well as in the ALK fusion gene, to be recorded on its local labelled platform. Investigator sites were also encouraged to additionally request $B R A F, H E R 2$ and PI3KCA mutation analyses, which are also routinely performed on these platforms. All centres were allowed to forego further mutation testing if one mutation known to exclude the others was found. The final, detailed results of these analyses were collected for each patient. We consulted the Catalogue of Somatic Mutations in Cancer for the purposes of categorising observed KRAS mutations in transversion $(\mathrm{G}>\mathrm{T}$ or $\mathrm{G}>\mathrm{C})$ or transition $(\mathrm{G}>\mathrm{A}$ or $\mathrm{T}>\mathrm{C})$. Given that most somatic mutations are mutually exclusive in the majority of lung cancer cases [11], we considered patients tested for at least EGFR and KRAS mutations, as well as ALK alterations, as "wild type", which was also optional for HER2, $B R A F$ and PIK3CA tests, and for no mutation found in any tested biomarkers.

\section{Statistics}

Categorical variables are presented as percentages. Proportion comparison was conducted with the Chi-squared test, if the expected count in each category was at least 5 , or with Fisher's exact test if not. To express the uncertainty of estimated probabilities, we have reported $95 \%$ Wilson confidence intervals. We used the one-sample Kolmogorov-Smirnov test to assess the plausibility of normal distribution assumption for continuous variables. Normally distributed continuous variables were expressed in mean and standard deviation. Means comparisons were performed applying the two-sided Student's t-test. Differences in distribution of continuous variables between two independent samples were assessed by the Mann-Whitney U-test. Continuous variables were also classed into tertile categories. We applied a binary logistic regression model to assess the risk of mutation for each considered gene. We generated three models: 1) unadjusted (crude odds ratios); 2) adjusted for sex and age only; and 3) comprehensively adjusted for the majority of potential confounding factors. Missing values were reported as such and all tests were two-sided. All statistics were performed by means of the SPSS V20 software (IBM SPSS Statistics, New York, USA).

\section{Results}

Population and passive smoking exposure

Of the 384 patients included in BioCAST, 334 presented complete data on overall passive smoke exposure and 219 (66\%) reported being "ever exposed" to passive smoke overall (domestic or workplace). At least one biomarker was tested in 313 patients (fig. 1). The main population characteristics are presented in table 1.

Overall, 283 index smokers were responsible for the passive smoke domestic exposure reported by 198 LCINS (122 patients reported an exposure beginning at childhood and 76 beginning during adulthood only) (table 2). Patients were exposed to a median (interquartile range) of 1 (1) index smoker. Most index smokers were parents (44\%) and spouses (47\%). In total, 60 patients reported exposure in their workplace. The median CDE was 24 (20) years in a domestic setting, 15 (25) years in the workplace and 26 (22) years overall. 
Profile of EGFR, KRAS and ALK according to passive smoke exposure

Overall, 127 somatic mutations were detected in 297 tested samples of the EGFR gene, 18 mutations in 256 samples of KRAS and 20 in 171 of $A L K$ rearrangement. The frequencies of somatic mutations in these biomarkers are presented according to exposure to overall passive smoke in table 3. There was no significant difference in any biomarker in terms of ever having been exposed to passive smoke compared to never having been exposured. When considering the CDE in years divided into tertiles, the frequency of EGFR mutation decreased as CDE increased (from 46\% in never-exposed patients to 39\% in highly exposed patients, defined as $>30$ years of cumulative exposure), though the difference was not statistically significant. Moreover, the frequency of $A L K$ rearrangement appeared to increase as the CDE increased (from $5 \%$ for the lowest tertile to $18 \%$ for the highest), while the frequency of alteration in never-exposed patients was $13 \%$.

Table 4 presents odds ratios for the likelihood of somatic mutation according to exposure to overall passive smoke for three logistic regression models. These are unadjusted, adjusted for age and sex, and additionally adjusted for body mass index, number of relatives with lung cancer, personal history of chronic bronchus diseases or respiratory infection, histology, definite occupational exposure, percentage of lifetime exposed to solid fuels for cooking and heating, and cooking dish-years (reflecting exposure to cooking oil fumes). As before, we found no significant association for any gene for ever versus never exposure. However, the previously found trend for EGFR mutation frequency decrease correlating with CDE increase remained, although still at statistically nonsignificant levels, as was the case for the $A L K$ trend.

There was no significant difference between female and male patients for any variables or biomarkers. Similarly, we found no significant results when restricting analysis to solely domestic or workplace exposure, nor when considering PSYs divided into tertiles (data not shown).

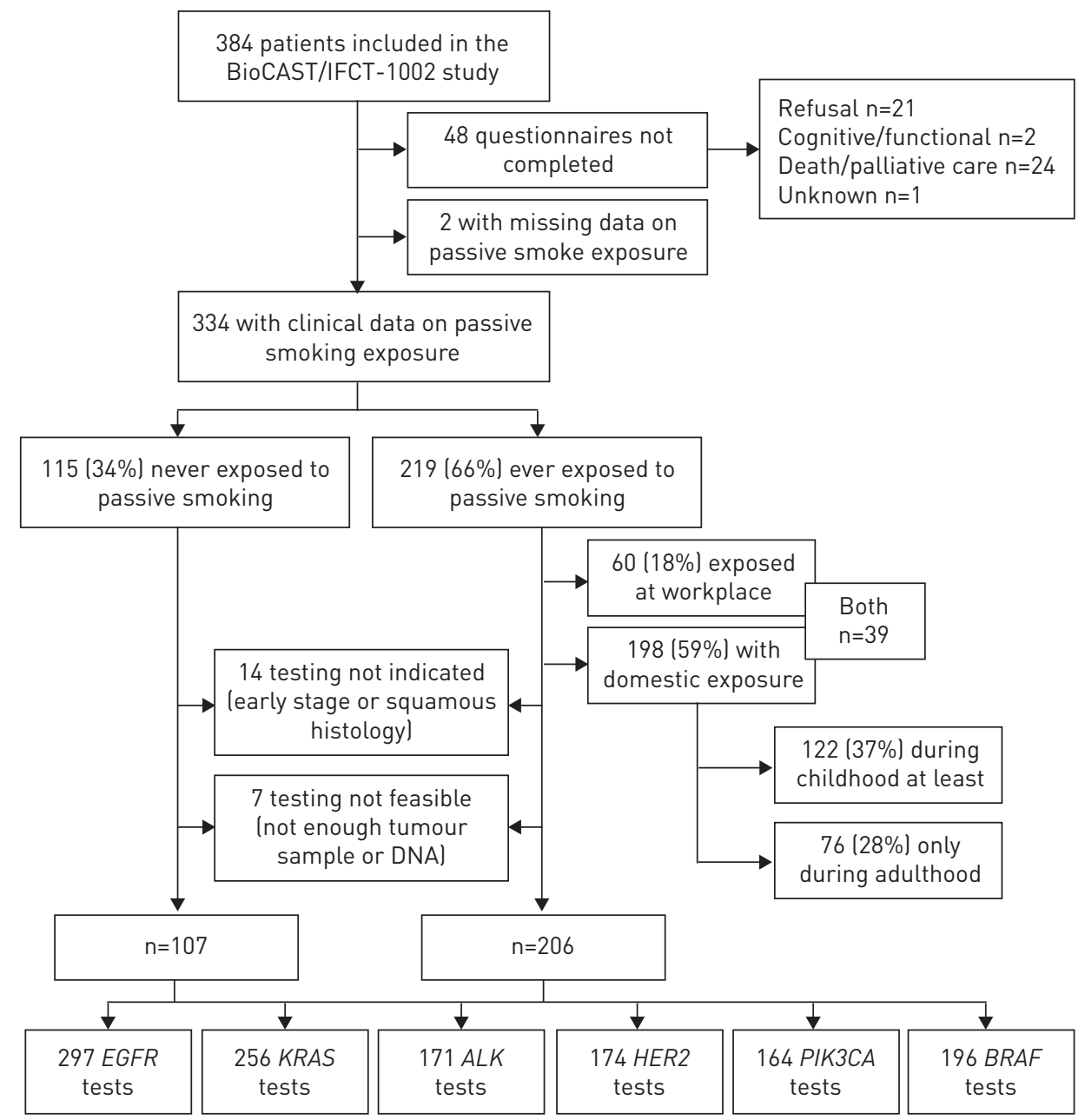

FIGURE 1 Study flow chart. EGFR: epidermal growth factor receptor; KRAS: Kirsten rat sarcoma viral oncogene homologue; ALK: anaplastic lymphoma kinase; HER2: human epidermal growth factor receptor 2; PIK3CA: phosphatidylinositol-3-kinase, catalytic subunit $\alpha$; BRAF: v-Raf murine sarcoma viral oncogene homologue B. 
TABLE 1 Main characteristics of the population according to overall exposure to passive smoking

\begin{tabular}{|c|c|c|c|c|}
\hline & All & Never exposed to passive smoking & Ever exposed to passive smoking" & p-value \\
\hline Males n (\%) & $58(17)$ & $30(26)$ & $28(13)$ & 0.002 \\
\hline \multicolumn{5}{|l|}{ Origin n (\%) } \\
\hline Europe & $302(90)$ & $105(91)$ & $197(90)$ & 0.690 \\
\hline Other & $32(10)$ & $10(9)$ & $22(10)$ & \\
\hline BMI $\mathrm{kg} \cdot \mathrm{m}^{-2}$ median (IQR) & $24(5)$ & $25(5)$ & $24(6)$ & 0.508 \\
\hline $0-1 \mathrm{n}(\%)$ & $252(76)$ & $95(83)$ & $157(72)$ & 0.022 \\
\hline$\geqslant 2 \mathrm{n}(\%)$ & 80 (24) & 19 (17) & $61(28)$ & \\
\hline Missing $n$ & 2 & 1 & 1 & \\
\hline \multicolumn{5}{|l|}{ Personal medical history $\mathrm{n}(\%)$} \\
\hline Any cancer & $62(19)$ & $20(17)$ & 42 (19) & 0.317 \\
\hline Chronic bronchial disease $^{+}$ & $49(15)$ & $16(14)$ & $33(15)$ & 0.777 \\
\hline Lung infection $\S$ & $112(34)$ & 43 (37) & $69(32)$ & 0.279 \\
\hline$\geqslant 10$ cooking dish-years ${ }^{\# \#} \mathrm{n}(\%)$ & $67(21)$ & $21(19)$ & $46(22)$ & 0.585 \\
\hline Missing $n$ & 12 & 5 & 7 & \\
\hline \multicolumn{5}{|l|}{ Definite occupational exposure } \\
\hline$\geqslant 1$ carcinogenic agent ${ }^{\text {}}$ ตी & $43(13)$ & $16(14)$ & $27(12)$ & 0.660 \\
\hline Missing $n$ & 1 & 1 & & \\
\hline Age at menarche ${ }^{++}$years median (IQR) & $13(2)$ & $13(2)$ & $13(2)$ & 0.871 \\
\hline Missing $n$ & 13 & 3 & 10 & \\
\hline Parity $^{++, \S \S}$ median (IQR) & $2(2)$ & $2(2)$ & $2(1)$ & 0.022 \\
\hline Age at first live birth ${ }^{++}$years median (IQR) & $23(5)$ & $24(5)$ & $23(5)$ & 0.331 \\
\hline Missing $n$ & 22 & 12 & 20 & \\
\hline Age at menopause ${ }^{++}$years median (IQR) & $50(7)$ & $50(5)$ & $50(7)$ & 0.584 \\
\hline Missing $n$ & 40 & 10 & 30 & \\
\hline I-IIIA n (\%) & $81(25)$ & $23(20)$ & $58(27)$ & 0.188 \\
\hline IIIB-IV n (\%) & $250(76)$ & $91(80)$ & 159 (73) & \\
\hline Missing $\mathrm{n}$ & 3 & 1 & 2 & \\
\hline
\end{tabular}

BMI: body mass index; IQR: interquartile range; HRT: hormone-replacement therapy; NOS: not otherwise specified. ${ }^{\#}$ : domestic and or workplace; $\AA^{\text {: }}$ first-degree biological relatives; ${ }^{+}$: includes asthma, chronic obstructive pulmonary disease, bronchiectasis and emphysema;

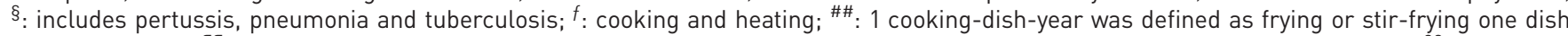
per day in 1 year; ${ }^{\text {१ी: }}$ includes asbestos, silica, chrome, diesel, paint and polycyclic aromatic hydrocarbons; ${ }^{++}$: among women only; ${ }^{\S \S}$ : live birth.

We observed no differences in the distribution of mutation type (based on exons in EGFR, and the transversion or transition mechanism for KRAS) according to the exposure to overall passive smoke (table 5). However, there was a nonsignificantly higher frequency of KRAS transversion in patients exposed to passive smoke compared with those who were never exposed ( $82 \%$ versus $60 \%$, respectively).

Profile of HER2, BRAF and PIK3CA according to passive smoke exposure

The univariate analysis results for low-frequency biomarkers have been provided in the table S1. We observed no significant association between somatic profile and exposure to passive smoke. Multivariate analyses were not performed due to the very low number of mutations and the expected wide $95 \%$ confidence intervals. 
TABLE 2 Exposure to passive smoking in the BioCAST population

\begin{tabular}{|c|c|c|c|c|c|}
\hline & \multicolumn{3}{|c|}{ Domestic exposure } & \multirow[t]{2}{*}{ Workplace exposure } & \multirow[t]{2}{*}{ Overall exposure $^{+}$} \\
\hline & Overall & Childhood $^{\#}$ & Adulthood" & & \\
\hline \multicolumn{6}{|l|}{ Exposure n (\%) } \\
\hline Ever & $198(59)$ & $122(37)$ & $76(23)$ & $60(18)$ & $219(66,95 \% \mathrm{Cl} 60-71)$ \\
\hline Index smokers $\mathrm{n}$ median (IQR) & $1(1)$ & & & $1(1)$ & \\
\hline Missing $n$ & & & & 12 & \\
\hline CDE years median (IQR) & $24(20)$ & $18(6)$ & $22(19)$ & $15(25)$ & $26(22)$ \\
\hline Missing $n$ & 4 & 5 & 1 & 1 & 3 \\
\hline
\end{tabular}

TABLE 3 Main somatic mutation profile according to exposure to passive smoking in univariate analysis

\begin{tabular}{|c|c|c|c|c|c|c|}
\hline & \multicolumn{2}{|l|}{$E G F R^{\#}$} & \multicolumn{2}{|l|}{$K R A S^{\pi}$} & \multicolumn{2}{|l|}{$A L K^{+}$} \\
\hline \multicolumn{7}{|c|}{ Exposure to passive smoking } \\
\hline Never & $46(46,95 \% \mathrm{Cl} 36-56)$ & 0.486 & $6(7,95 \%$ Cl 3-15) & 0.867 & $7(13,95 \% \mathrm{Cl} 6-26)$ & 0.726 \\
\hline Ever & $81(41,95 \%$ Cl 34-49) & & $12(7,95 \% \mathrm{Cl} 4-13)$ & & $13(11,95 \% \mathrm{Cl} 6-19)$ & \\
\hline \multicolumn{7}{|c|}{ Cumulative duration of exposure } \\
\hline Never & $46(46)$ & 0.866 & $6(7)$ & NC & 7 (13) & NC \\
\hline$>30$ years & 25 (39) & & $4(8)$ & & $6(18)$ & \\
\hline Missing & 3 & & 1 & & 2 & \\
\hline \multicolumn{7}{|l|}{ Time of exposure } \\
\hline Never & $53(45)$ & 0.799 & $8(8)$ & 0.940 & $7(11)$ & 0.522 \\
\hline Childhood & $45(41)$ & & $6(7)$ & & $10(15)$ & \\
\hline Adulthood only & $29(43)$ & & 4 (7) & & $3(8)$ & \\
\hline Never & $53(45)$ & 0.542 & $8(8)$ & $0.458^{f}$ & $7(11)$ & $0.533^{f}$ \\
\hline Ever & $74(41)$ & & $10(7)$ & & $13(12)$ & \\
\hline \multicolumn{7}{|c|}{ Childhood exposure } \\
\hline Never $\S$ & $82(44)$ & 0.550 & $12(7)$ & 0.784 & $10(10)$ & 0.320 \\
\hline Ever & $45(41)$ & & $6(7)$ & & $10(15)$ & \\
\hline
\end{tabular}

p-values were calculated by the Chi-squared test unless otherwise stated. EGFR: epidermal growth factor receptor; KRAS: Kirsten rat sarcoma viral oncogene homologue; ALK: anaplastic lymphoma kinase; NC: not computable. ${ }^{\#}$ : 297 tested samples; ${ }^{\text {ๆ}: ~} 256$ tested samples; ${ }^{+}: 171$ tested samples; ${ }^{\S}$ : never-exposed to passive smoking and exposed during adulthood only; ${ }^{f}$ : Fisher test.

Overall somatic profile

Figure 2 presents the frequency of mutation for each biomarker tested, according to CDE for passive smoke and in never-smokers never exposed to passive smoke.

Overall, 248 patients underwent a full biomarker analysis. The mutation profile, categorised by passive smoke exposure, is presented in figure S1. Once more, we observed the same trend for a decreasing frequency of EGFR mutation correlating with CDE increase. Interestingly, "wild-type" status often tended to increase along with $\mathrm{CDE}$. The frequency of multiple mutations (more than one mutation in different genes) was stable across all categories. 
TABLE 4 Odds ratios for somatic mutation according to passive smoking exposure and cumulative duration of exposure

\begin{tabular}{|c|c|c|c|c|c|c|}
\hline & \multicolumn{2}{|c|}{ Crude } & \multicolumn{2}{|c|}{ Adjusted for age and sex } & \multicolumn{2}{|c|}{ Comprehensively adjusted ${ }^{\#}$} \\
\hline & OR $(95 \% \mathrm{CI})$ & p-value & aOR $(95 \% \mathrm{CI})$ & p-value & aOR $(95 \% \mathrm{CI})$ & p-value \\
\hline \multicolumn{7}{|l|}{ EGFR } \\
\hline Ever & $0.84(0.52-1.37)$ & 0.49 & $0.81(0.49-1.32)$ & 0.40 & $0.80(0.47-1.36)$ & 0.41 \\
\hline Never & 1.00 & & 1.00 & & 1.00 & \\
\hline \multicolumn{7}{|c|}{ Cumulative duration of exposure } \\
\hline$>30$ years & $0.77(0.41-1.45)$ & 0.41 & $0.71(0.37-1.37)$ & 0.31 & $0.68(0.34-1.37)$ & 0.28 \\
\hline \multicolumn{7}{|l|}{ KRAS } \\
\hline \multicolumn{7}{|c|}{ Exposure to passive smoking } \\
\hline Ever & $1.09(0.40-3.01)$ & 0.87 & 1.09 (0.39-3.05) & 0.87 & $1.11(0.34-3.60)$ & 0.86 \\
\hline Never & 1.00 & & 1.00 & & 1.00 & \\
\hline \multicolumn{7}{|c|}{ Cumulative duration of exposure } \\
\hline \multicolumn{7}{|l|}{$A L K$} \\
\hline \multicolumn{7}{|c|}{ Exposure to passive smoking } \\
\hline Ever & $0.84(0.31-2.24)$ & 0.73 & $0.76(0.28-2.09)$ & 0.60 & $1.35(0.39-4.71)$ & 0.64 \\
\hline Never & 1.00 & & 1.00 & & 1.00 & \\
\hline \multicolumn{7}{|c|}{ Cumulative duration of exposure } \\
\hline$\leqslant 20$ years & $0.36(0.07-1.85)$ & 0.22 & $0.35(0.07-1.81)$ & 0.21 & $0.64(0.10-4.08)$ & 0.64 \\
\hline $20-30$ years & $0.71(0.19-2.60)$ & 0.60 & $0.64(0.17-2.39)$ & 0.50 & $1.05(0.22-5.02)$ & 0.95 \\
\hline$>30$ years & $1.44(0.44-4.71)$ & 0.55 & $1.28(0.38-4.39)$ & 0.69 & $3.26(0.71-14.95)$ & 0.13 \\
\hline \multicolumn{7}{|c|}{$\begin{array}{l}\text { aOR: adjusted odds ratio; EGFR: epidermal growth factor receptor; KRAS: Kirsten rat sarcoma viral oncogene homologue; ALK: anaplastic } \\
\text { lymphoma kinase. \#: adjusted for sex (binary), age (continuous), body mass index (continuous), number of relatives with lung cancer } \\
\text { (continuous), personal history of chronic bronchus diseases (binary), personal history of respiratory infection (binary), histology } \\
\text { ladenocarcinoma, squamous cell carcinoma or other), definite exposure to any main bronchus carcinogen (binary), percentage of lifetime } \\
\text { exposed to solid fuels for cooking and heating (continuous), and cooking dish-years (continuous). }\end{array}$} \\
\hline
\end{tabular}

\begin{tabular}{|c|c|c|c|}
\hline & Never exposed & Ever exposed & p-value \\
\hline \multicolumn{4}{|l|}{ EGFR } \\
\hline Mutation in exon 18 & $0(0)$ & $3(4)$ & NC \\
\hline Mutation in exon 19 & $27(60)$ & $49(60)$ & \\
\hline Mutation in exon 20 & $2(4)$ & $3(4)$ & \\
\hline Mutation in exon 21 & $14(31)$ & $24(30)$ & \\
\hline Double mutation in EGFR gene & $2(4)$ & $2(2)$ & \\
\hline Missing & 1 & & \\
\hline \multicolumn{4}{|l|}{ KRAS } \\
\hline Transition ${ }^{\#}$ & $2(40)$ & $2(18)$ & 0.547 \\
\hline Transversion $\rrbracket$ & $3(60)$ & 9 (82) & \\
\hline Missing & 1 & 1 & \\
\hline
\end{tabular}

Data are presented as $\mathrm{n}(\%)$ or $\mathrm{n}$, unless otherwise stated. EGFR: epidermal growth factor receptor; KRAS: Kirsten rat sarcoma viral oncogene homologue; NC: not computable. \#: G13D, G12G or G12D; ๆ: G12V, G12R or G12A.

\section{Discussion}

In this study, we demonstrated that the mutation profile was not affected by exposure to passive smoke in a French population of never-smoker lung cancer sufferers for any biomarker of the tested (EGFR, KRAS, HER2, BRAF, PIK3CA and ALK). 


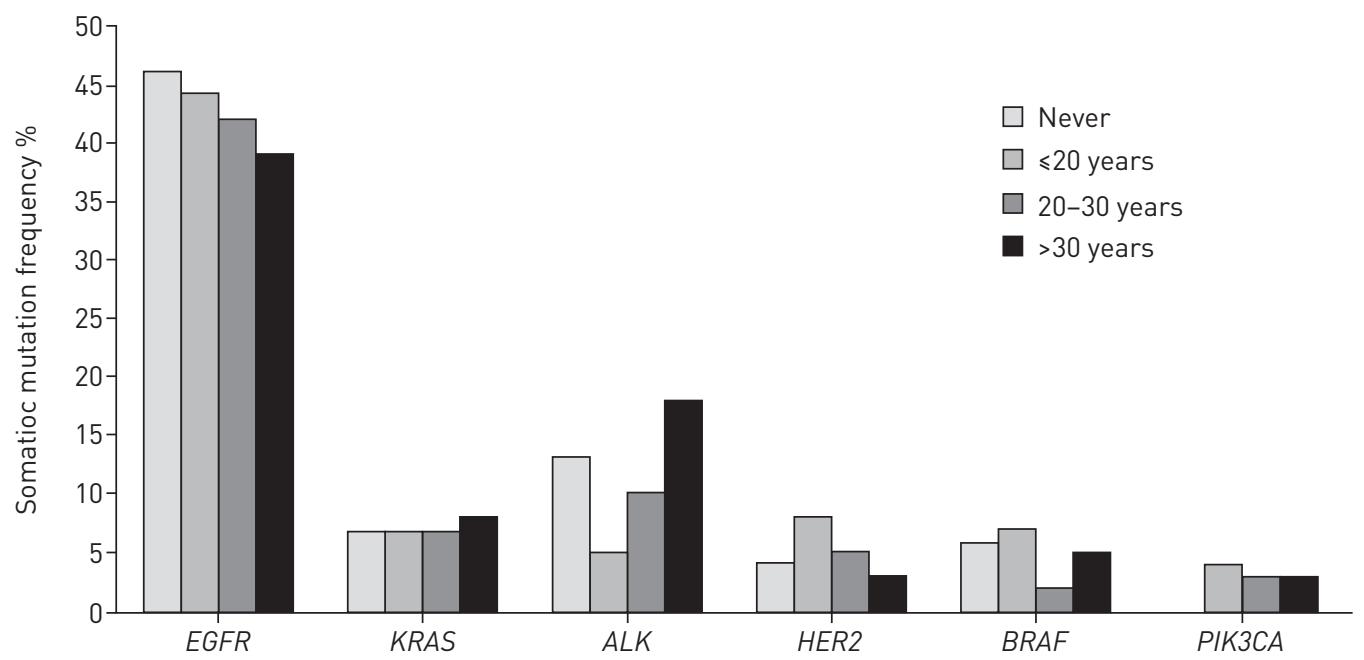

FIGURE 2 Somatic mutation pattern according to exposure to passive smoke for EGFR (epidermal growth factor receptor), KRAS (Kirsten rat sarcoma viral oncogene homologue), ALK (anaplastic lymphoma kinase), HER2 (human epidermal growth factor receptor 2), BRAF (v-Raf murine sarcoma viral oncogene homologue B) and PIK3CA (phosphatidylinositol-3-kinase, catalytic subunit $\alpha$ ).

There have been studies previously focused on this topic, such as the study by LeE et al. [13] involving 179 consecutive Asian LCINS patients with detailed self-reported data on environmental tobacco smoke exposure. Those authors found that passive smoke exposure negatively correlated with EGFR mutation frequency in a multivariate logistic regression model adjusted for sex and histology. That study also reported a trend for a dose-response relationship with PSYs, with a decreasing frequency of EGFR mutation observed when PSYs increased (OR for the highest quartile: 0.22, 95\% CI 0.08-0.62). These results were consistent with those previously reported by TAM et al. [16] in 241 patients (all smoking statuses included), proving that passive smoke exposure tends to decrease the probability of EGFR mutation compared with never-smoking alone in univariate analysis $(61.1 \%$ versus $74.8 \%$, respectively; $\mathrm{p}=0.257$ ). However, KaWAGUCHI et al. [14] reported contrasting findings in a population of 126 Asian LCINS. They demonstrated that EGFR mutation frequency increased significantly among increasing CDE quintiles. In a multivariate model, which took into account sex, age and family history of cancer, they showed that $\mathrm{CDE}$ was positively linked to the incidence of an EGFR-activating mutation. The same team reported similar results at the 2013 World Lung Cancer Congress in 498 LCINS of various ethnicities (425 from Asia). EGFR mutation was again positively associated, in a multivariate model, with CDE, though only in women (OR 1.084, 95\% CI 1.003-1.171 $(\mathrm{p}=0.0422)$ for each 10 -year CDE increase) [22]. Finally, TAGA et al. [15] reported their findings for 143 never- and long-term former smokers from two US cohorts. They observed a higher EGFR mutation frequency among patients who were not exposed to passive smoking compared with exposed patients in one of the two cohorts, while they found the opposite in the second cohort.

All these conflicting results could be explained by the inherent difficulty in accurately reporting passive-smoke exposure [23]. In all these studies, including our own, passive smoking is only self-reported by the patients. A biological assessment of passive smoking, such as blood plasma or urine cotinine concentration measurement [4], or even urinary 4-(methylnitrosamino)-1-(3-pyridyl)-1-butanol and its glucuronides [24], may be more reliable, yet is also more costly and thus not used in our study, nor in the other previously mentioned studies. Furthermore, biological assessment is only relevant for current, not former, exposure. The frequency of overall passive-smoke exposure differs strongly between each of these studies, despite a common definition: 135 (75\%) out of 179 patients in the study by LEe et al. [13], 73 (51\%) out of 143 patients in that by TAGA et al.[15], 124 (98\%) out of 126 patients in that by KAWAGUSHI et al. [14] (445 (89\%) out of 498 in the latest update [22]), 19 (9\%) out of 241 patients in that by TAM et al.[16] and 219 (66\%) out of 334 patients in our study. Moreover, some bias, such as memorisation or redaction bias. could occur when reporting this exposure. In addition, dose and duration variables may also be inappropriate for accurately assessing cumulative exposure. As an example, in our cohort, a barman exposed daily to passive smoking from many smokers over 10 years was unable to enumerate the number of index smokers to whom he had been exposed. Thus, we were only able to compute the CDE, which was 10 years. In contrast, someone exposed to two index smokers at the same time would have a CDE that was twice as long (20 years) as that of the the barman. Similar concerns may occur for the PSY 
variable. In addition, the population in which the studies were conducted differed from study to study, ranging from Asian only $[13,14,16]$ to primarily Caucasian $[7,15]$, and from never-smoker only $[13,14]$ to all smoking statuses mixed [16]. These differences may also account for the conflicting results, as genomic susceptibility and confounding related to risk-factor exposure could differ depending on geographical origin $[2,25]$.

With the exception of EGFR, other oncogenes have been poorly investigated in this setting. KRAS mutation frequency was found not to differ between never-smokers and passive smokers (3.6\% versus $0 \%$, respectively; $\mathrm{p}=1.000$ ) in one study [16]. In addition, KuBo et al. [22] and RyAN et al. [26] reported no association between passive smoke exposure and the frequency of $A L K$ rearrangement.

Our findings suggest that passive smoking exposure is not the only risk factor for lung cancer in never-smokers, and possibly not the leading one either. This actually constitutes one of the possible reasons why mutation spectrum is not affected by indirect smoking exposure. These findings are in line with recent observations obtained by whole-genome sequencing [27]. Thus, some other risk factor may be suspected in this setting, such as environmental pollution (including natural radon and atmospheric pollution), occupational exposure, domestic pollution (cooking and heating fumes, or cooking oil), personal history of cancer or respiratory disease, or familial history of cancer supporting the role of genetic factors [2]. As BioCAST has a large dataset on exposure to these factors, we will fully explore these issues in further analysis. Electronic cigarettes should also be closely assessed for lung cancer risk in future studies.

Our study had some limitations. Firstly, the biomarker analyses were not centrally performed and used different processes depending on the centre. However, the performance and concordance of sample processing and mutation screening methods across participating centres had previously been investigated in blinded cross-validation studies, producing good results [21]. Secondly, except for EGFR, the number of mutations was low for all oncogenes, ranging from 18 for KRAS to four for PIK3CA. Our study may therefore lack power yet, to our knowledge, our cohort remains the largest and most comprehensive of its field in a European population. However, European descents are heterogeneous. Thirdly, we had to deal with some missing values, especially PSYs, along with the biomarker mutation testing, in which missing value rates ranged from $11 \%$ for EGFR to $51 \%$ for PIK3CA (fig. 1). Nevertheless, all missing values have been reported as such in the results section.

Our study also had some strengths. Firstly, inclusion was strictly restricted to never-smokers. In addition, we recorded a substantial amount of data about potential confounders and were able to compute a more comprehensive adjustment for most of them than other studies have. Secondly, this represents the largest study involving almost exclusively European-descent patients. It is also the first reported study investigating six of the major lung cancer oncogenes, namely EGFR, KRAS, HER2, BRAF, PIK3CA and $A L K$, concomitantly regarding passive smoke exposure. Thirdly, we collected all indicators of passive smoke exposure used in previous studies, such as CDE, PSYs, childhood exposure, etc., in order to provide an easy and comprehensive comparison with others.

In conclusion, never-smoker patients with lung cancer exposed to passive smoke were found to not carry a smoker-like somatic mutation profile in terms of EGFR, KRAS, HER2, BRAF, PIK3CA and ALK together when compared to unexposed never-smoker patients. Passive smoking alone appeared to be insufficient to determine a somatic profile in lung cancer.

\section{Acknowledgements}

The authors' affiliations are as follows. Sébastien Couraud: Acute Respiratory Medicine and Thoracic Oncology Unit, Lyon Sud hospital, Hospices Civils de Lyon, Pierre Bénite, and Faculty of Medicine Lyon-Sud Charles Mérieux, Lyon 1 University, Oullins, France; Didier Debieuvre: Pulmonology and Thoracic Oncology Unit, Emile Muller hospital, Centre Hospitalier de Mulhouse, Mulhouse, France; Lionel Moreau: Respiratory Medecine, Hopitaux Civils, Colmar, France; Patrick Dumont: Respiratory Medicine and Thoracic Oncology Unit, Chauny Hospital, Chauny, France; Jacques Margery: Service des Maladies Respiratoires, Hôpital d'Instruction des Armées Percy, Clamart, France; Elisabeth Quoix: Department of Pneumology, NHC, Université de Strasbourg, Strasbourg, France; Bernard Duvert: Respiratory Medicine, Montélimar Hospital, Montélimar, France; Laurent Cellerin: Service de Pneumologie, Institut du Thorax, CHU de Nantes, Nantes, France; Nathalie Baize: Pôle des Spécialités Médicales et Chirurgicales Intégrées, Centre Hospitalier Universitaire d'Angers, Angers, France; Bruno Taviot: Centre Médical Nicolas de Pontoux, Chalon sur Saône, France; Marie Coudurier: Pulmonology Unit and Thoracic Oncology Unit, Chambery Hospital, Chambery, France; Jacques Cadranel: AP-HP, Hôpital Tenon, Service de Pneumologie, and Sorbonne Université, UPMC Univ. Paris 06, GRC 04 Theranoscan, Paris, France; Pascale Missy: Intergroupe Francophone de Cancérologie Thoracique, Paris, France; Franck Morin: Intergroupe Francophone de Cancérologie Thoracique, Paris, France; Jean-François Mornex: Université Lyon 1, INRA UMR754, Hospices Civils de Lyon, Lyon, France; Gérard Zalcman: Pulmonology and Thoracic Oncology Dept, Caen University Hospital, UMR INSERM 1086, Caen Basse Normandie University, Caen, France; Pierre-Jean Souquet: Acute Respiratory Medicine and Thoracic Oncology Unit, Lyon Sud hospital, Hospices Civils de Lyon, Pierre Bénite, and Faculty of Medicine Lyon-Sud Charles Mérieux, Lyon 1 University, Oullins, France.

The collaborators in the BioCAST/IFCT-1002 study were Pierre-Jean Souquet (Hospices Civiles de Lyon (HCL), Hôpital Lyon Sud, Lyon, France), Radj Gervais (Centre François Baclesse, Caen, France), Hélène Doubre (Hôpital Foch, 
Suresnes, France), Eric Pichon (Centre Hospitalier Universitaire (CHU) de Tours, Tours, France), Adrien Dixmier (Centre Hospitalier $(\mathrm{CH})$ d'Orléans, Orleans, France), Isabelle Monnet (Centre Hospitalier Intercommunal (CHI) de Créteil, Creteil, France), Bénédicte Mastroianni (HCL, Hôpital Louis Pradel, Lyon), Michel Vincent (Hôpital Saint-Joseph, Lyon, France), Jean Tredaniel (Hôpital Saint Joseph, Paris, France), Marielle Perrichon (CH de Bourg-en-Bresse, Bourg-en-Bresse, France), Pascal Foucher (CHU Bocage, Dijon, France), Bruno Coudert (Centre Georges-François Leclerc, Dijon, France), Denis Moro-Sibilot (CHU de Grenoble, Grenoble, France), Eric Dansin (Centre Oscar Lambret, Lille, France), Patrick Dumont ( $\mathrm{CH}$ de Chauny, Chauny, France), Lionel Moreau ( $\mathrm{CH}$ de Colmar, Colmar, France), Didier Debieuvre ( $\mathrm{CH}$ de Mulhouse, Mulhouse, France), Jacques Margery (Hôpital d'Instructions des Armées (HIA) Percy, Clamart, France), Élisabeth Quoix (CHU de Strasbourg, Nouvel Hôpital Civil, Strasbourg, France), Bernard Duvert (CH de Montélimar, Montelimar, France), Laurent Cellerin (CHU de Nantes, Hôpital Nord Laennec, Nantes, France), Nathalie Baize (CHU d'Angers, Angers, France), Bruno Taviot (CM Nicolas de Pontoux, Chalon-sur-Saône, France), Marie Coudurier ( $\mathrm{CH}$ Chambéry, Chambery, France), Jacques Cadranel (Assistance Publique (AP) Hôpitaux de Paris (HP), Hôpital Tenon, Paris), Patrick Chatellain (CH d'Annemasse, Ambilly, France), Jérôme Virally (CHI d'Aulnay-Sous-Bois, Aulnay-Sous-Bois, France), Virginie Westeel (CHU de Besançon, Besancon, France), Sylvie Labrune (AP-HP, Hôpital Ambroise Paré, Boulogne, France), Laureline Le Maignan de Kerangat (CHG Le Mans, Le Mans, France), Jean-Marc Dot (HIA Desgenettes, Lyon, France), Sébastien Larive (CH de Mâcon, Macon, France), Christos Chouaid (AP-HP, Hôpital Saint-Antoine, Paris, France), Daniel Coëtmeur (CHG de Saint-Brieuc, Saint-Brieuc, France), Clarisse Audigier-Valette (CHI de Toulon, Toulon, France), Jean-Pierre Gury (CHI de Vesoul, Vesoul, France), Luc Odier (CH de Villefranche sur Saône, Villefranche sur Saône, France), Gérard Zalcman (CHU de Caen, Caen, France), Yannick Duval (CH de Cannes, Cannes, France), Patrick Merle (CHU de Clermont-Ferrand, Clermont-Ferrand, France), Gilles Devouassoux (HCL, Hôpital de la Croix Rousse, Lyon, France), Reza Azarian ( $\mathrm{CH}$ de Versailles, Versailles, France), Patricia Barre ( $\mathrm{CH}$ de Cahors, Cahors, France), Olivier Raffy (CH de Chartres, Chartres, France), Philippe Masson ( $\mathrm{CH}$ de Cholet, Cholet, France), Stéphanie Dehette ( $\mathrm{CH}$ de Compiègne, Compiègne, France), Caroline Toussaint Batbedat ( $\mathrm{CH}$ de Lagny-sur-Marne, Jossigny, France), Gérard Oliviero ( $\mathrm{CH}$ de Longjumeau, Paris, France), Marc Derollez (Polyclinique du Parc, Maubeuge, France), Nadine Paillot (CHR de Metz, Thionville, France), Jérôme Dauba (CH de Mont De Marsan, Mont De Marsan, France), Dominique Herman ( $\mathrm{CH}$ de Nevers, Nevers, France), Jean-Michel Rodier (AP-HP, Hôpital Bichat, Paris, France), Suzanna Bota (CHU de Rouen, Rouen, France), Philippe Brun ( $\mathrm{CH}$ de Valence, Valence, France), Geneviève Letanche (Clinique de Vénissieux, Vénissieux, France), Mohamed Khomsi ( $\mathrm{CH}$ d'Annonay, Annonay, France), Béatrice Gentil-Lepecq (CH de Bourgoin-Jallieu, Bourgoin-Jallieu, France), Philippe Ravier (Cabinet de Pneumologie, Dijon, France), Yassine Hammou (Clinique Mutualiste, Lyon, France), Fabrice Barlesi (AP-HM, Hôpital Nord, Marseille, France), Hélène Laize (CH de Rambouillet, Rambouillet, France), Pierre Fournel (Institut de Cancérologie de la Loire, Saint-Priest en Jarez, France), Christelle Clement-Duchene (CHU de Nancy, Vandoeuvre-Les-Nancy, France), Joël Castelli (CHD Castelluccio, Ajaccio, France), Sophie Schneider ( $\mathrm{CH}$ de Bayonne, Bayonne, France), Antoine Levy (CH Jacques Cœur, Bourges, France), Jérôme Dauba (CH de Dax, Dax, France), Geneviève Jolimoy (Centre d'Oncologie et de Radiothérapie du Parc, Dijon, France), Hervé Pegliasco (Fondation Hôpital Ambroise Paré, Marseille, France), Michel Poudenx (Centre Antoine Lacassagne, Nice, France), Alain Prevost (Institut Jean-Godinot, Reims, France), Philippe Romand (CH de Thonon-les-Bains, Thonon-les-Bains, France) and Laurence Bigay-Game (CHU de Toulouse, and Etienne SUC, Clinique St Jean Languedoc, Toulouse, France).

This work was presented as an oral communication at the 15th World Conference on Lung Cancer in Sydney, Australia, on October 29, 2013: Couraud S. Souquet P-J, Paris C, et al. J Thorac Oncol 2013; 8: Suppl. 2, S207-S208.

The authors wish to thank Stéphanie Labonne (research assistant) and William Lebossé (junior research assistant) (IFCT, Paris, and Lyon University Hospital, Lyon, France), who conducted the patient interviews; M. Quan Tran and Antoine Deroy (IFCT, Paris, France); all investigators in the 75 BioCAST participating centres; and the patients and their families who greatly contributed to this work by giving their time for answering the questionnaire and interview questions.

\section{References}

1 Oberg M, Jaakkola MS, Woodward A, et al. Worldwide burden of disease from exposure to second-hand smoke: a retrospective analysis of data from 192 countries. Lancet 2011; 377: 139-146.

2 Couraud S, Zalcman G, Milleron B, et al. Lung cancer in never smokers - a review. Eur J Cancer 2012; 48: 1299-1311.

3 Hackshaw AK, Law MR, Wald NJ. The accumulated evidence on lung cancer and environmental tobacco smoke. BMJ 1997; 315: 980-988

4 Vineis P, Airoldi L, Veglia F, et al. Environmental tobacco smoke and risk of respiratory cancer and chronic obstructive pulmonary disease in former smokers and never smokers in the EPIC prospective study. BMJ 2005; 330: 277.

5 Brennan P, Buffler PA, Reynolds P, et al. Secondhand smoke exposure in adulthood and risk of lung cancer among never smokers: a pooled analysis of two large studies. Int J Cancer 2004; 109: 125-131.

6 Clément-Duchêne C, Vignaud J-M, Stoufflet A, et al. Characteristics of never smoker lung cancer including environmental and occupational risk factors. Lung Cancer 2010; 67: 144-150.

7 Couraud S, Souquet P-J, Paris C, et al. BioCAST/IFCT-1002: Epidemiological and molecular features of lung cancer in never-smokers. Eur Respir J 2015; 45: 1403-1414.

8 Pao W, Girard N. New driver mutations in non-small-cell lung cancer. Lancet Oncol 2011; 12: 175-180.

9 Mazieres J, Peters S, Lepage B, et al. Lung cancer that harbors a HER2 Mutation: epidemiologic characteristics and therapeutic perspectives. J Clin Oncol 2013; 31: 1997-2003.

10 Shaw AT, Yeap BY, Mino-Kenudson M, et al. Clinical features and outcome of patients with non-small-cell lung cancer who harbor EML4-ALK. J Clin Oncol 2009; 27: 4247-4253.

11 Mounawar M, Mukeria A, Le Calvez F, et al. Patterns of EGFR, HER2, TP53, and KRAS mutations of p14 ${ }^{\text {arf }}$ expression in non-small cell lung cancers in relation to smoking history. Cancer Res 2007; 67: 5667-5672.

12 Paik PK, Arcila ME, Fara M, et al. Clinical characteristics of patients with lung adenocarcinomas harboring BRAF mutations. J Clin Oncol 2011; 29: 2046-2051. 
13 Lee YJ, Cho BC, Jee SH, et al. Impact of environmental tobacco smoke on the incidence of mutations in epidermal growth factor receptor gene in never-smoker patients with non-small-cell lung cancer. J Clin Oncol 2010; 28: 487-492.

14 Kawaguchi T, Ando M, Kubo A, et al. Long exposure of environmental tobacco smoke associated with activating EGFR mutations in never-smokers with non-small cell lung cancer. Clin Cancer Res 2011; 17: 39-45.

15 Taga M, Mechanic LE, Hagiwara N, et al. EGFR somatic mutations in lung tumors: radon exposure and passive smoking in former- and never-smoking U.S. women. Cancer Epidemiol Biomarkers Prev 2012; 21: 988-992.

16 Tam IY, Chung LP, Suen WS, et al. Distinct epidermal growth factor receptor and KRAS mutation patterns in non-small cell lung cancer patients with different tobacco exposure and clinicopathologic features. Clin Cancer Res 2006; 12: 1647-1653.

17 Couraud S, Souquet P-J, Paris C, et al. The BioCAST/IFCT-1002 study: a comprehensive overview of demographic, risk exposure and somatic mutations of non-small cell lung cancer occurring among French never smokers. J Thorac Oncol 2013; 8: Suppl. 2, S207-S208.

18 Couraud S, Labonne S, Missy P, et al. BioCAST: le Bio-observatoire national du cancer bronchiques chez les patients non fumeurs (IFCT1002) [Lung cancer in never smokers: A French national cohort (BioCAST/ IFCT-1002)]. Rev Mal Respir 2013; 30: 576-583.

19 Bourgkard E, Wild P, Gonzalez M, et al. Comparison of exposure assessment methods in a lung cancer case-control study: performance of a lifelong task-based questionnaire for asbestos and PAHs. Occup Environ Med 2013; 70: 884-891.

20 Nowak F, Soria J-C, Calvo F. Tumour molecular profiling for deciding therapy-the French initiative. Nat Rev Clin Oncol 2012; 9: 479-486.

21 Beau-Faller $\mathrm{M}$, Blons $\mathrm{H}$, Domerg $\mathrm{C}$, et al. A multicenter blinded study evaluating EGFR and KRAS mutation testing methods in the clinical non-small cell lung cancer setting - IFCT/ERMETIC2 Project Part 1: comparison of testing methods in 20 French molecular genetic National Cancer Institute platforms. J Mol Diagn 2014; 16: $45-55$.

22 Kubo A, Masahiko A, Ross S, et al. Impacts of environmental tobacco smoke on EGFR mutations and ALK rearrangements in never smokers with non-small cell lung cancer: analyses on a prospective multinational ETS registry. J Thorac Oncol 2013; 8: Suppl. 2, S1-S1410.

23 Besaratinia A, Pfeifer GP. Second-hand smoke and human lung cancer. Lancet Oncol 2008; 9: 657-666.

24 Thomas JL, Guo H, Carmella SG, et al. Metabolites of a tobacco-specific lung carcinogen in children exposed to secondhand or thirdhand tobacco smoke in their homes. Cancer Epidemiol Biomarkers Prev 2011; 20: 1213-1221.

25 Bennett WP, Alavanja MC, Blomeke B, et al. Environmental tobacco smoke, genetic susceptibility, and risk of lung cancer in never-smoking women. J Natl Cancer Inst 1999; 91: 2009-2014.

26 Ryan BM, Wang Y, Jen J, et al. Evidence that the lung Adenocarcinoma EML4-ALK fusion gene is not caused by exposure to secondhand tobacco smoke during childhood. Cancer Epidemiol Biomarkers Prev 2014; 23: $1432-1434$

27 Krishnan VG, Ebert PJ, Ting JC, et al. Whole-genome sequencing of Asian lung cancers: second-hand smoke unlikely to be responsible for higher incidence of lung cancer among Asian never-smokers. Cancer Res 2014; 74: 6071-6081. 